\title{
Randomised study of adjuvant chemotherapy for completely resected p-stage I-IIIA non-small cell lung cancer
}

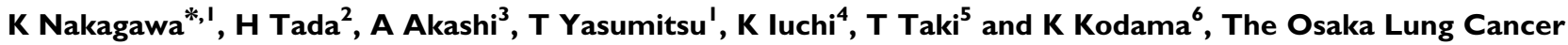 \\ Study Group, Japan \\ 'Department of Thoracic Surgery, Osaka Prefectural Medical Center for Respiratory and Allergic Diseases, 3-7-I Habikino, Habikino 583-8588, Japan; \\ ${ }^{2}$ Department of Pulmonary Surgery, Osaka City General Hospital, Osaka 534-0021, Japan; ${ }^{3}$ Department of Thoracic Surgery, Takarazuka Municipal \\ Hospital, Takarazuka 665-0827, Japan; ${ }^{4}$ Department of Surgery, National Kinki Central Hospital for Chest Diseases, Sakai 59I-8555, Japan; \\ ${ }^{5}$ Department of Thoracic Surgery, Kitano Hospital, The Tazuke Kofukai Medical Research Institute, Osaka 530-8480, Japan; ${ }^{6}$ Department of Thoracic \\ Surgery, Osaka Medical Center for Cancer and Cardiovascular Diseases, Osaka 537-85 I I, Japan
}

We evaluated the therapeutic usefulness of adjuvant chemotherapy in patients with completely resected non-small cell lung cancer (NSCLC). We also examined the relation between DNA ploidy pattern and the response to chemotherapy. A total of 267 patients with NSCLC (pathologically documented stage I, II, or IIIA) underwent complete resection, and DNA ploidy pattern was analysed. Patients with stage I disease $(n=172)$ were randomly assigned to receive surgery alone (group A) or surgery followed by adjuvant chemotherapy (UFT (oral anti-cancer drug, a combination of Uracil and Tegaful) $400 \mathrm{mg}^{\text {day }}{ }^{-1}$ for I year after surgery; group B). Stage II or IIIA disease patients $(n=95)$ were randomly assigned to surgery alone (group $C$ ) or surgery followed by chemotherapy (two 28-day courses of cisplatin $80 \mathrm{mg} \mathrm{m}^{-2}$ on day I plus vindesine $3 \mathrm{mg} \mathrm{m}^{-2}$ on days I and 8 , followed by UFT $400 \mathrm{mg}$ day $^{-1}$ for at least I year; group D). Eight-year overall survival rate in patients with stage I disease was $74.2 \%$ (95\% confidence interval (Cl): $64.4-$ $84.0 \%)$ in group $B$ and $57.6 \%$ (95\% Cl: $46.4-68.8 \%)$ in group $A(P=0.045$ by log-rank test). In patients with stage II and IIIA disease, no difference was found between groups $C$ and D. Analysis according to DNA ploidy pattern revealed no difference between the groups. Postoperative chemotherapy with UFT was suggested to be useful in patients with completely resected stage I NSCLC. No difference was seen in relation to DNA pattern in any treatment group.

British Journal of Cancer (2006) 95, 817-82I. doi:10.1038/sj.bjc.6603336 www.bjcancer.com

Published online 12 September 2006

(c) 2006 Cancer Research UK

Keywords: adjuvant chemotherapy; complete resection; non-small cell lung cancer; DNA ploidy pattern; randomised controlled trial; UFT

A meta-analysis of postoperative chemotherapy in non-small cell lung cancer (NSCLC) reported by the British Medical Council in 1995 found that adjuvant chemotherapy did not adequately improve outcome in this condition (Non-small Cell Lung Cancer Collaborative Group, 1995). Despite a number of trials since, the value of postoperative chemotherapy for NSCLC remains controversial (Wada et al, 1996; Endo et al, 2003; Scagliotti et al, 2003). Beginning around 1990, considerable attention has been focused on DNA ploidy pattern as a possible new prognostic factor, with tumours showing aneuploidy, associated with a poor prognosis, reported to show a better response to chemotherapy than those showing diploidy (Granone et al, 1993; Salvati et al, 1994; Kim et al, 1996). However, these previous studies were based on retrospective data.

\footnotetext{
*Correspondence: Dr K Nakagawa;

E-mail: katuhiro@hbk.pref.osaka.jp

We dedicate this paper to the late Dr Takashi Mori, who died before completion of the study.

See Appendix.

Received 5 May 2006; revised 27 July 2006; accepted 27 July 2006; published online 12 September 2006
}

Here, we investigated the usefulness of postoperative adjuvant chemotherapy for the management of NSCLC patients prospectively assigned to treatment on the basis of DNA ploidy.

\section{PATIENTS AND METHODS}

\section{Eligibility criteria}

Eligibility criteria included an untreated primary lung cancer; histologically confirmed diagnosis of squamous cell carcinoma, adenocarcinoma, or large cell carcinoma; pathologically documented stage I, II, or IIIA disease; diploidy or aneuploidy on analysis of nuclear DNA of the primary tumour; age 75 years or younger in patients with stage I disease or 70 years or younger in those with stage II or IIIA disease; Eastern Cooperative Oncology Group (ECOG) performance status of 0,1 , or 2 ; and adequate organ function as defined by a leucocyte count of at least $4000 \mathrm{~mm}^{-3}$, platelet count of at least $100000 \mathrm{~mm}^{-3}$, serum haemoglobin level of at least $10 \mathrm{~g} \mathrm{dl}^{-1}$, serum aspartate aminotransferase (AST) level of not more than $100 \mathrm{U}$, alanine aminotransferase (ALT) level of at most $100 \mathrm{U}$, albumin/globulin ratio of at least 1.0 , serum creatinine level of less than $1.5 \mathrm{mg} \mathrm{dl}^{-1}$, and serum urea nitrogen level of not 
more than $25 \mathrm{mg} \mathrm{dl}^{-1}$. Further, patients with a serious concurrent condition were also excluded. All tumours were resected by pulmonary resection consisting of at least lobectomy and systematic hilar/mediastinal lymph node dissection. Cases of complete resection were defined as those without macroscopic residual tumour or microscopic positive margins. The study was reviewed and approved by the institutional review boards of each participating centre, and written informed consent was obtained from all patients.

Because stage I disease differs considerably from stage II and IIIA disease, assignment of similar treatments would have negatively affected outcome. Patients with stage II or IIIA disease were therefore assigned to receive different treatment from those with stage I disease.

\section{Measurement of DNA ploidy}

Samples were harvested and frozen immediately after tumour excision. Nuclear DNA content was measured by flow cytometry and evaluated by an independent flow cytometry evaluation committee who were blinded to patient data.

\section{Treatment schedule}

Patients were grouped according to stage as follows. For stage I patients, Group A (control) received no adjuvant chemotherapy but was followed after surgery, whereas Group B received single daily oral administration of UFT (oral anti-cancer drug, a combination of Uracil and Tegaful) at $400 \mathrm{mg} \mathrm{day}^{-1}$ for at least 1 year starting 3-6 weeks after surgery.

For stages II and IIIA, Group C (control) received no adjuvant chemotherapy but was followed after surgery, whereas Group D was given two 28-day courses of chemotherapy with cisplatin $\left(80 \mathrm{mg} \mathrm{m}^{-2}\right)$ on day 1 and vindesine $\left(3 \mathrm{mg} \mathrm{m}^{-2}\right)$ on days 1 and 8 , starting 3-6 weeks after surgery, followed by single daily oral administration of UFT at $400 \mathrm{mg} \mathrm{day}^{-1}$ for at least 1 year.

Adverse effects of chemotherapy were evaluated using the National Cancer Institute Common Toxicity Criteria (version 2.0, Jan 30,1998$)$ and handled by appropriate treatment, discontinuation of UFT, or both. In Group D, chemotherapy after the administration of vindesine on day 8 of the first course was continued only after confirmation that white blood cell count was greater than 3000. Other anticancer drugs, immunomodulators, and radiotherapy were not used unless recurrence was confirmed.

\section{Treatment assignment}

Patients were stratified on the basis of pathological stage, histologic type, and ploidy pattern, and then randomly assigned to groups. Randomisation was performed centrally, with assignment for pathological $\mathrm{T}$ and $\mathrm{N}$ stage balanced using the minimisation method with probability and the method of Zelen (Yonekura et al, 1999; Tanaka et al, 2002).

\section{Statistical analysis}

The primary end point was overall survival, defined as the time from surgery until death from any cause. The secondary end point was disease-free survival, defined as the time from surgery until relapse or death from any cause, whichever occurred first.

Survival curves were calculated by the Kaplan-Meier method (Kaplan and Meier, 1958), and statistical significance of differences between groups was compared with the log-rank test (Peto et al, 1977). $P$-values of less than 0.05 were considered to indicate significance. Multivariable analysis to estimate the simultaneous effects of prognostic factors on survival was carried out with the Cox proportional-hazards model. Categorical variables were compared using the $\chi^{2}$ test.
Target numbers of patients were calculated as follows. Based on previous studies (Kuwahara et al, 1989; The Study Group of Adjuvant Chemotherapy for Lung Cancer, 1995; Wada et al, 1996), the assumed 5-year survival in the control group was $75 \%$ in stage I patients and $40 \%$ in stage II or III patients. The expected survival improvement was $15 \%$ in stage I patients and $25 \%$ in stage II or III patients.

On the basis of Freedman's sample size table (Freedman, 1982), the sample size required to detect a significant difference between surgery alone and surgery plus chemotherapy at a power of 0.8 and a $5 \%$ level of significance was 169 patients with stage I disease and 102 with stage II, or III disease.

One goal of this study was to compare survival in patients with aneuploid tumours who received chemotherapy after surgery with that in patients who received surgery alone. Given an aneuploid to diploid tumour ratio of 8:2 (Yamaoka et al, 1991), 80\% of stage I, II, and III cases were estimated to be aneuploid. The required number of cases was therefore estimated to be 212 cases of stage I disease and 128 cases of stage II or III disease. Allowing for $8 \%$ ineligibility and loss to follow-up, the target number was set at 230 patients with stage I and 140 with stage II or III disease.

All statistical analyses were carried out using the SAS software package ver. 7 (SAS Institute Inc, Cary, NC, USA).

\section{RESULTS}

A total of 287 patients were enrolled at 15 centres from April 1992 to March 1994. At this time, a number of new induction chemotherapy protocols for early stage lung cancer were introduced in Japan, hampering the further accrual of patients, and enrollment was therefore stopped in March 1994. This report evaluates cases followed until the end of November 2001.

Of the 287 patients enrolled, 20 were excluded because they did not meet the entry criteria, namely conditions other than cancer (inflammatory or benign tumours) or non-curative resection. Median follow-up time of the 267 patients studied was 7.4 years.

\section{Clinical characteristics}

Of 172 patients with stage I disease, 87 were assigned to group A and 85 to group $B$, with no significant difference between them in sex, mean age, performance status, $\mathrm{T}$ stage, histologic type, or tumour DNA pattern.

Of 95 patients with stage II $(n=33)$ or IIIA $(n=62)$ disease, 48 were assigned to group $C$ and 47 to group $D$, with no significant difference between them in sex, mean age, performance status, $\mathrm{T}$ stage, $\mathrm{N}$ stage, pathologically determined disease stage, histologic type, or DNA pattern (Table 1).

\section{Treatment rate}

A $100 \%$ treatment rate was defined as at least 1 year of continuous treatment with $400 \mathrm{mg}$ of UFT daily. From this, individual rates were calculated as (number of UFT administration days)/ $365 \times($ daily UFT dosage $) / 400 \times 100$. Mean treatment rates in groups B and D were estimated to be 76.7 and $48.6 \%$, respectively. In group D, 39 patients were given one or more courses of cisplatin and vindesine (one course in three patients, two in 36). Treatment compliance was $83.0 \%$. Treatment was not given to eight patients owing to patient refusal in two, postoperative complications in two, and poor general condition in four.

\section{Survival rate}

Eight-year overall survival rate in stage I patients was 57.6\% (95\% confidence interval (CI): $46.4-68.8 \%$ ) in group A (control) and $74.2 \%(95 \%$ CI: $64.4-84.0 \%)$ in group B, with a significant 
Table I Patient characteristics

\begin{tabular}{|c|c|c|c|c|c|c|}
\hline & $\mathbf{A}$ & B & Total & C & D & Total \\
\hline Sex & 87 & 85 & 172 & 48 & 47 & 95 \\
\hline Male & 49 & 49 & 98 & 35 & 35 & 70 \\
\hline Female & 38 & 36 & 74 & 13 & 12 & 25 \\
\hline \multicolumn{7}{|l|}{ Age } \\
\hline (Ave.) & 60.9 & 60.2 & 60.6 & 59.3 & 60.5 & 59.9 \\
\hline \multicolumn{7}{|l|}{ PS } \\
\hline 0 & 66 & 66 & 132 & 36 & 35 & 71 \\
\hline I & 19 & 19 & 38 & 12 & 10 & 22 \\
\hline 2 & 2 & 0 & 2 & 0 & 2 & 2 \\
\hline \multicolumn{7}{|l|}{ pT } \\
\hline I & 41 & 45 & 86 & 12 & 13 & 25 \\
\hline 2 & 46 & 40 & 86 & 24 & 24 & 48 \\
\hline 3 & & & & 12 & 10 & 22 \\
\hline \multicolumn{7}{|l|}{ pN } \\
\hline 0 & & & & 6 & 1 & 7 \\
\hline I & & & & 18 & 19 & 37 \\
\hline 2 & & & & 24 & 27 & 51 \\
\hline \multicolumn{7}{|l|}{ Stage } \\
\hline I & 87 & 85 & 172 & & & \\
\hline ॥ & & & & 16 & 17 & 33 \\
\hline$\| \mathrm{A}$ & & & & 32 & 30 & 62 \\
\hline \multicolumn{7}{|l|}{ Histology } \\
\hline Adenocarcinoma & 67 & 68 & 135 & 29 & 27 & 56 \\
\hline Squamous cell carcinoma & 17 & 15 & 32 & 17 & 17 & 34 \\
\hline Large cell carcinoma & 3 & 2 & 5 & 2 & 3 & 5 \\
\hline \multicolumn{7}{|l|}{ DNA pattern } \\
\hline Diploidy & 18 & 17 & 35 & 10 & 8 & 18 \\
\hline Aneuploidy & 69 & 68 & 137 & 38 & 39 & 77 \\
\hline
\end{tabular}

Abbreviations: PS, performance status; $\mathrm{pT}$, pathological tumour stage; $\mathrm{pN}$, pathological lymph node stage.

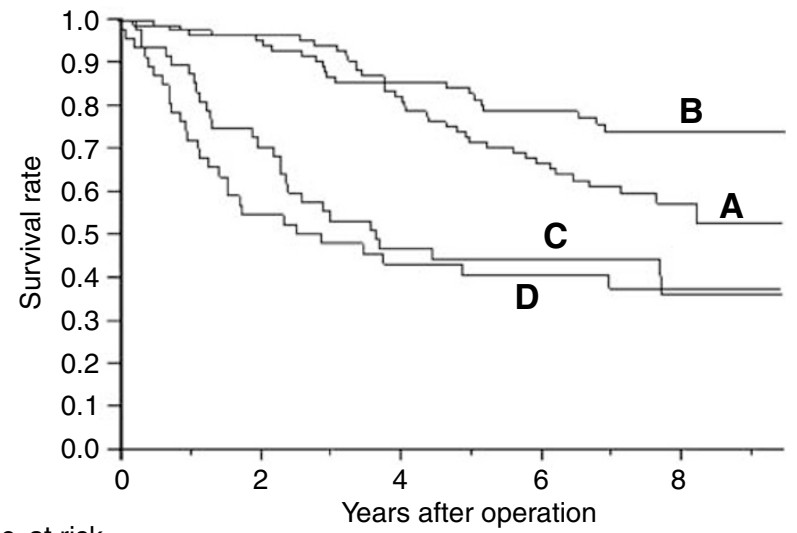

No. at risk

$\begin{array}{llllll}\text { Group A } & 87 & 84 & 70 & 53 & 19 \\ \text { Group B } & 85 & 81 & 68 & 57 & 19 \\ \text { Group C } 48 & 33 & 22 & 16 & 8 \\ \text { Group D } & 47 & 25 & 18 & 14 & 8\end{array}$

Figure I Overall survival of stage I control and UFT group patients. Eight-year survival rate was $57.6 \%$ for the control group $\mathbf{A}(n=87)$ and $74.2 \%$ for the UFT group B $(n=85)$. A significant difference in survival curves for these groups is seen ( $P=0.045$ by log-rank test).
Table 2 Overall survival in the control and UFT groups

\begin{tabular}{|c|c|c|c|c|c|}
\hline & \multicolumn{2}{|c|}{ No. of cases } & \multicolumn{2}{|c|}{ 8-year survival rate (\%) } & \multirow[b]{2}{*}{$P$-value } \\
\hline & $\mathbf{A}$ & B & $\mathbf{A}$ & B & \\
\hline \multicolumn{6}{|l|}{ Sex } \\
\hline Female & 38 & 36 & 74.7 & 78.0 & 0.850 \\
\hline Male & 49 & 49 & 43.6 & 71.6 & 0.013 \\
\hline \multicolumn{6}{|l|}{ Age (years) } \\
\hline$<60$ & 38 & 37 & 74.5 & 84.8 & 0.171 \\
\hline$\geqslant 60$ & 49 & 48 & 45.9 & 65.4 & 0.153 \\
\hline \multicolumn{6}{|l|}{ PS } \\
\hline 0 & 66 & 66 & 62.0 & 78.3 & 0.055 \\
\hline 1,2 & 21 & 19 & 43.4 & 62.2 & 0.460 \\
\hline \multicolumn{6}{|l|}{$p T$} \\
\hline TI & 41 & 44 & 56.4 & 87.7 & 0.014 \\
\hline $\mathrm{T} 2$ & 46 & 40 & 59.4 & 58.5 & 0.763 \\
\hline \multicolumn{6}{|l|}{ Histology } \\
\hline Adeno carcinoma & 67 & 68 & 60.2 & 75.6 & 0.065 \\
\hline Non-adeno carcinoma & 20 & 17 & 51.7 & 69.3 & 0.503 \\
\hline \multicolumn{6}{|l|}{ DNA pattern } \\
\hline Diploidy & 18 & 17 & 53.5 & 86.7 & 0.078 \\
\hline Aneuploidy & 69 & 68 & 59.0 & 71.3 & 0.158 \\
\hline
\end{tabular}

Abbreviations: PS, performance status; $\mathrm{PT}$, pathological tumour stage.

difference seen between the two survival curves $(P=0.045$; Figure 1). Respective rates in Groups C and D were $36.8 \%(95 \%$ CI: $21.3-52.3 \%$ ) and $38.0 \%$ (95\% CI: $23.5-52.5 \%$ ), with no significant difference between these two overall survival curves $(P=0.52)$. Moreover, no significant difference was seen in 8-year disease-free survival rate between groups $\mathrm{A}$ and $\mathrm{B}$ or $\mathrm{C}$ and $\mathrm{D}$.

\section{Subgroup analyses}

When subgrouped by histology, the adenocarcinoma subgroup showed no significant difference in overall survival curves between groups $\mathrm{A}$ and $\mathrm{B}(P=0.065)$; or between patients in groups $\mathrm{A}$ and $\mathrm{B}$ with diploid tumours $(P=0.078)$ or aneuploid tumours $(P=0.16)$ (Table 2). Moreover, overall survival curves in this adenocarcinoma subgroup did not differ significantly between groups $\mathrm{C}$ and D (group C, $n=29,8$-year survival rate $41.3 \%, 95 \%$ CI: $21.9-60.7 \%$; group D, $n=27$, 8-year survival rate $40.0 \%$, 95\% CI: $19.9-60.0 \%$; $P=0.98)$.

When subgrouped by DNA pattern, no significant difference in overall survival curve was seen in diploid tumour patients in groups $\mathrm{C}$ and $\mathrm{D}$ (group C, $n=10$, 8-year survival rate $30.0 \%, 95 \%$ CI: $1.6-58.4 \%$; group $\mathrm{D}, n=8,8$-year survival rate $37.5 \%, 95 \% \mathrm{CI}$ : $4.0-71.0 \% ; P=0.92)$; or between aneuploid patients in groups $\mathrm{C}$ and D (group C, $n=38$, 8-year survival rate $36.8 \%$, 95\% CI: $17.8-$ $55.8 \%$; group D, $n=39$, 8-year survival rate $38.1 \%$, $95 \%$ CI: 21.8 $54.4 \% ; P=0.44)$.

\section{Multivariate analysis}

Multivariate analysis indicated that UFT treatment was a significant predictor of outcome in stage I patients, following age and sex (Table 3).

\section{Adverse effects}

Grade 3 anorexia occurred in one patient in group B. The incidence of grade 3 and 4 toxicity was only $1.2 \%$ in group B. In 
group $\mathrm{D}$, grade 3 or 4 leucopenia was seen in seven patients $(14.6 \%)$, anorexia in three patients $(6.3 \%)$, nausea/vomiting in two patients $(4.2 \%)$, and hair loss in one patient $(2.1 \%)$ (Table 4$)$. No episode lasted more than 1 month.

There were no lethal adverse effects in either chemotherapy group.

\section{Mortality}

Twenty-six of 87 patients (29.9\%) in group A and 14 of 85 (16.5\%) in group $B$ died of their tumours, with this difference being significant $(P=0.037)$. Nine patients in group $A$ and six in group $B$ died of causes other than cancer, with this difference not significant $(P=0.45)$.

The rate of mortality from cancer was $52.1 \%$ in group $\mathrm{C}$ and $42.6 \%$ in group $\mathrm{D}$, with this difference not significant $(P=0.35)$. The rate of mortality from other causes was $6.3 \%$ in group $\mathrm{C}$ and $17.0 \%$ in group $\mathrm{D}$, again without significance $(P=0.10)$.

\section{DISCUSSION}

UFT is an oral fluorinated dihydropyrimidine preparation which combines tegafur, a prodrug of 5-fluorouracil, with uracil, an inhibitor of dihydropyrimidine dehydrogenase, the enzyme which catalyses the metabolism of 5-fluorouracil. One reason for the effectiveness of postoperative adjuvant chemotherapy with UFT in patients with completely resected stage I lung cancer is the action of tegafur. The metabolism of tegafur results in prolongation of

Table 3 Multivariate analysis of outcomes

\begin{tabular}{lccc}
\hline Factor & Hazard ratio & $\mathbf{9 5 \%} \mathbf{C l}$ & P-value \\
\hline $\begin{array}{l}\text { Sex } \\
\text { Female } \\
\text { Male }\end{array}$ & 1 & & \\
$\begin{array}{l}\text { Age (years) } \\
<60\end{array}$ & 1.95 & $1.11-3.60$ & 0.019 \\
$\geqslant 60$ & 1 & & \\
$\begin{array}{l}\text { Group } \\
\text { Control } \\
\text { UFT }\end{array}$ & 2.24 & $1.26-4.20$ & 0.0053 \\
\hline
\end{tabular}

active levels of 5-fluorouracil, and its metabolites (GHB and GBL) promote angiogenesis (Yonekura et al, 1999; Basaki et al, 2001; Tanaka et al, 2002). Meta-analysis of several randomised controlled studies has confirmed that UFT is therapeutically useful. The Japan Lung Cancer Research Group (JLCRG) performed Phase III randomised controlled studies of postoperative adjuvant chemotherapy with UFT in patients with stage I adenocarcinoma of the lung, and showed significant improval in survival, with a hazard ratio of 0.71 (95\% CI: $0.52-0.98)$ as compared with surgery alone in this subgroup $(P=0.04)$ (Kato et al, 2004).

Our study enrolled a wider range of patients than the JLCRG study, including not only adenocarcinoma and completely resected stage I NSCLC, but also stage II and IIIA NSCLC. Survival in patients with stage I disease was significantly better in group B than in group A $(P=0.045)$. On analysis by histologic tumour type, survival in patients with adenocarcinoma was slightly but not significantly better in group B $(P=0.065)$. In contrast, survival in patients with diploid tumours did not differ between group A and $B$, probably because of the low patient numbers, which were insufficient for statistical analysis ( $n=18$ and 17 , respectively). The number of patients with diploid tumour was small as compared with that of patients with aneuploid tumour, and was insufficient for statistical analysis in the present study.

In stage II and III adenocarcinoma, in contrast, no difference in survival was seen either overall, or by ploidy. These results therefore suggest that UFT is effective for the management of stage I lung cancer, consistent with the findings of the WJSG 2nd study and the JLCRG study (Kato et al, 2004).

Early studies of DNA ploidy (Granone et al, 1993; Salvati et al, 1994; Kim et al, 1996) reported that aneuploidy is an independent predictor of poor outcome. In contrast, more recent investigations (Fujino et al, 1996; Bellotti et al, 1997; Reinmuth et al, 2000; Pelletier et al, 2001) have questioned the value of ploidy as a prognostic factor. Statistical analysis of the prognostic implications of diploidy was precluded in the present study owing to the low number of patients with diploid tumours (stage I, $n=35$; stage II and III, $n=18$ ).

With regard to the efficacy of the present therapeutic regimen, a meta-analysis of the usefulness of postoperative cisplatin-based adjuvant chemotherapy in NSCLC found good efficacy in stage II and III patients receiving cisplatin-based $\left(320 \mathrm{mg} \mathrm{m}^{-2}\right.$ or more) chemotherapy with vinorelbine (Pignon et al, 2006). In contrast, the dose of cisplatin in the present study was as low as $160 \mathrm{mg} \mathrm{m}^{-2}$ and vindesine was used as a combination drug. These differences

Table 4 Toxicity

\begin{tabular}{|c|c|c|c|c|c|c|c|c|c|c|c|}
\hline Toxicity $(n=85)$ & \multicolumn{4}{|c|}{ Grade } & Frequency of $\mathbf{G} 3$ or $\mathbf{G} 4$ (\%) & Toxicity $(n=47)$ & \multicolumn{4}{|c|}{ Grade } & Frequency of $\mathbf{G} 3$ or $\mathbf{G} 4$ (\%) \\
\hline Leucopenia & 8 & 2 & 0 & 0 & & Leucopenia & 8 & 11 & 5 & 2 & 14.6 \\
\hline Thrombocytopenia & 2 & 0 & 0 & 0 & & Thrombocytopenia & 3 & 2 & 0 & 0 & \\
\hline Anaemia & I & 0 & 0 & 0 & & Anaemia & 8 & 6 & 0 & 0 & \\
\hline Anorexia & 10 & 8 & I & 0 & 1.2 & BUN & 5 & 0 & 0 & 0 & \\
\hline Nausea/vomiting & 8 & 1 & 0 & 0 & & Creatinine & 2 & 0 & 0 & 0 & \\
\hline Diarrhoea & 3 & 1 & 0 & 0 & & Anorexia & 10 & 14 & 3 & 0 & 6.3 \\
\hline Stomatitis & 4 & 0 & 0 & 0 & & Nausea/vomiting & 12 & 4 & 2 & 0 & 4.2 \\
\hline Pigmentation & 6 & 0 & 0 & 0 & & Diarrhoea & 4 & 1 & 0 & 0 & \\
\hline Alopecia & 0 & 1 & 0 & 0 & & Stomatitis & 4 & 0 & 0 & 0 & \\
\hline
\end{tabular}

Abbreviations: BUN, blood urea nitrogen; CDDP, cisplatin; VDS, vindesine sulfate. 
are likely associated with the insufficient efficacy seen here. Further, the response rate to UFT in unresectable NSCLC has been reported as only $8 \%$ (Keicho et al, 1986), and usefulness of postoperative adjuvant chemotherapy has been described for relatively early-stage NSCLC only. The possibility therefore exists that UFT may have insufficient efficacy in stage II/III disease with high malignancy.

In conclusion, although the relation between DNA ploidy pattern and the response to postoperative adjuvant chemotherapy remains unclear, our results suggest that

\section{REFERENCES}

Basaki Y, Chikahisa L, Aoyagi K, Miyadera K, Yonekura K, Hashimoto A, Okabe S, Wierzba K, Yamada Y (2001) Gamma-hydroxybutyric acid and 5-fluorouracil, metabolites of UFT, inhibit the angiogenesis induced by vascular endothelial growth factor. Angiogenesis 4: 163-173

Bellotti M, Elsner B, Paez De Lima A, Esteva H, Marchevsky AM (1997) Neural networks as a prognostic tool for patients with non-small cell carcinoma of the lung. Mod Pathol 10: 1221-1227

Endo C, Saito Y, Iwanami H, Tsushima T, Imai T, Kawamura M, Kondo T, Koike K, Handa M, Kanno R, Fujimura S (2003) A randomized trial of postoperative UFT therapy in $p$ stage I, II non-small cell lung cancer: North-east Japan Study Group for Lung Cancer Surgery. Lung Cancer 40: $181-186$

Freedman LS (1982) Tables of the number of patients required in clinical trials using the logrank test. Stat Med 1: 121-129

Fujino S, Enokibori T, Tezuka N, Asada Y, Inoue S, Kato H, Mori A (1996) A comparison of epidermal growth factor receptor levels and other prognostic parameters in non-small cell lung cancer. Eur J Cancer 32A: $2070-2074$

Granone P, Cardillo G, Rumi E, D'Ugo D, Rumi C, Ciletti S, Margaritora S, Terribile D, Picciocchi A (1993) DNA flow cytometric analysis in patients with operable non-small cell lung carcinoma. Eur J Cardiothorac Surg 7: 351-355

Kaplan E, Meier P (1958) Non-parametric estimation from incomplete observations. J Am Stat Assoc 53: 457-481

Kato H, Ichinose Y, Ohta M, Hata E, Tsubota N, Tada H, Watanabe Y, Wada H, Tsuboi M, Hamajima N, Ohta M (2004) A randomized trial of adjuvant chemotherapy with uracil-tegafur for adenocarcinoma of the lung. N Engl J Med 350: 1713-1721

Keicho N, Saijo N, Shinkai T, Eguchi K, Sasaki Y, Tamura T, Sakurai M, Sano T, Hoshi A (1986) Phase II study of UFT in patients with advanced non-small cell lung cancer. Jpn J Clin Oncol 16: 143-146

Kim YC, Park KO, Kim HJ, Choi IS, Park CS, Juhng SW (1996) DNA ploidy and proliferative activity in bcl-2 expressed non-small cell lung cancer. Korean J Intern Med 11: 101-107

Kuwahara O, Doi O, Mori T, Yasumitsu T, Kuwahara M, Nakahara K, Kurata M, Sagara N, Sawamura K (1989) The study of adjuvant chemotherapy of non-small cell lung cancer: The result of prospective randomized control study. Jpn J Lung Cancer 29: 453 (abstr)

Non-small Cell Lung Cancer Collaborative Group (1995) Chemotherapy in non-small cell lung cancer: a meta-analysis using updated data on individual patients from 52 randomised clinical trials. Non-small Cell Lung Cancer Collaborative Group. BMJ 311: 899-909

\section{Appendix A}

- Osaka University, Faculty of Medicine

- Osaka Medical Center for Cancer and Cardiovascular Diseases

- Osaka Prefectural Medical Center for Respiratory and Allergic Diseases

- Kansai Medical University

- Kansai Electric Power Hospital postoperative adjuvant chemotherapy with UFT improves survival and is therapeutically useful in patients with completely resected stage I NSCLC.

\section{ACKNOWLEDGEMENTS}

We thank Professor J Patrick Barron of the International Medical Communications Center of Tokyo Medical University for his review of this manuscript.
Pelletier MP, Edwardes MD, Michel RP, Halwani F, Morin JE (2001) Prognostic markers in resectable non-small cell lung cancer: a multivariate analysis. Can J Surg 44: 180-188

Peto R, Pike MC, Armitage P, Breslow NE, Cox DR, Howard SV, Mantel N, McPherson K, Peto J, Smith PG (1977) Design and analysis of randomized clinical trials requiring prolonged observation of each patient. II. analysis and examples. Br J Cancer 35: 1-39

Pignon JP, Tribodet H, Scagliotti GV, Douillard JY, Shepherd FA, Stephens RJ, Le Chevalier T, on behalf of the LACE Collaborative Group (2006) Lung adjuvant cisplatin evaluation (LACE): a pooled analysis of five randomized clinical trials including 4,584 patients. J Clin Oncol (Meeting Abstracts) 24: 7008

Reinmuth N, Brandt B, Kunze WP, Junker K, Thomas M, Achatzy R, Scheld $\mathrm{HH}$, Semik M (2000) Ploidy, expression of erbB1, erbB2, P53 and amplification of erbB1, erbB2 and erbB3 in non-small cell lung cancer. Eur Respir J 16: 991 - 996

Salvati F, Teodori L, Trinca ML, Pasquali-Lasagni R, Gohde W (1994) The relevance of flow-cytometric DNA content in the evaluation of lung cancer. J Cancer Res Clin Oncol 120: 233-239

Scagliotti GV, Fossati R, Torri V, Crino L, Giaccone G, Silvano G, Martelli M, Clerici M, Cognetti F, Tonato M (2003) Randomized study of adjuvant chemotherapy for completely resected stage I, II, or IIIA non-small-cell Lung cancer. J Natl Cancer Inst 95: 1453-1461

Tanaka F, Wada H, Fukushima M (2002) Antiangiogenic effect of UFT and its clinical significance in postoperative adjuvant therapy for NSCLC. Proc Am Soc Clin Oncol 21: 2669 (abstr)

The Study Group of Adjuvant Chemotherapy for Lung Cancer (Chubu Japan) (1995) A randomized trial of postoperative adjuvant chemotherapy in non-small cell lung cancer (the second cooperative study). Eur J Surg Oncol 21: 69-77

Wada H, Hitomi S, Teramatsu T (1996) Adjuvant chemotherapy after complete resection in non-small-cell lung cancer. West Japan Study Group for Lung Cancer Surgery. J Clin Oncol 14: 1048-1054

Yamaoka N, Uchiyama Y, Taniguchi H (1991) Flow cytometric nuclear DNA analysis in resected primary adenocarcinoma of the lung and applications to prognosis and adjuvant chemotherapy. Jpn J Chest Surg (In Japanese) 5: $498-506$

Yonekura K, Basaki Y, Chikahisa L, Okabe S, Hashimoto A, Miyadera K, Wierzba K, Yamada Y (1999) UFT and its metabolites inhibit the angiogenesis induced by murine renal cell carcinoma, as determined by a dorsal air sac assay in mice. Clin Cancer Res 5: $2185-2191$

- Kinki University School of Medicine

- Toneyama National Hospital

- National Kinki Central Hospital for Chest Diseases

- Sumitomo Hospital

- Takarazuka Municipal Hospital

- Kitano Hospital The Tazuke Kofukai Medical Research Institute

- Osaka City General Hospital

- Hyogo College of Medicine 